\title{
Potential factors contributing to the poor antimicrobial efficacy of SAAP-148 in a rat wound infection model
}

\author{
Gabrielle S. Dijksteel ${ }^{1,4^{*}}$, Magda M. W. Ulrich ${ }^{1,4}$, Marcel Vlig ${ }^{1}$, Peter H. Nibbering ${ }^{2}$, Robert A. Cordfunke ${ }^{3}$,
} Jan W. Drijfhout ${ }^{3}$, Esther Middelkoop ${ }^{1,4}$ and Bouke K. H. L. Boekema ${ }^{1}$

\begin{abstract}
Background: We investigated the efficacy of a synthetic antimicrobial peptide SAAP-148, which was shown to be effective against Methicillin-resistant Staphylococcus aureus (MRSA) on tape-stripped mice skin. Unexpectedly, SAAP148 was not effective against MRSA in our pilot study using rats with excision wounds. Therefore, we investigated factors that might have contributed to the poor efficacy of SAAP-148. Subsequently, we optimised the protocol and assessed the efficacy of SAAP-148 in an adapted rat study.
\end{abstract}

Methods: We incubated $100 \mu \mathrm{L}$ of SAAP-148 with $1 \mathrm{~cm}^{2}$ of a wound dressing for $1 \mathrm{~h}$ and determined the unabsorbed volume of peptide solution. Furthermore, $10^{5}$ colony forming units (CFU)/mL MRSA were exposed to increasing dosages of SAAP-148 in 50\% (v/v) human plasma, eschar- or skin extract or PBS. After 30 min incubation, the number of viable bacteria was determined. Next, ex vivo skin models were inoculated with MRSA for $1 \mathrm{~h}$ and exposed to SAAP-148. Finally, excision wounds on the back of rats were inoculated with $10^{7} \mathrm{CFU}$ MRSA overnight and treated with SAAP-148 for $4 \mathrm{~h}$ or $24 \mathrm{~h}$. Subsequently, the number of viable bacteria was determined.

Results: Contrary to Cuticell, Parafilm and Tegaderm film, $<20 \%$ of peptide solution was recovered after incubation with gauze, Mepilex border and Opsite Post-op. Furthermore, in plasma, eschar- or skin extract $>20$-fold higher dosages of SAAP-148 were required to achieve a 2-log reduction (LR) of MRSA versus SAAP-148 in PBS. Exposure of ex vivo models to SAAP-148 for $24 \mathrm{~h}$ resulted in a 4 -fold lower $L R$ than a $1 \mathrm{~h}$ or $4 \mathrm{~h}$ exposure period. Additionally, SAAP-148 caused a 1.3-fold lower mean LR at a load of $10^{7} \mathrm{CFU}$ compared to $10^{5}$ CFU MRSA. Moreover, exposure of ex vivo excision wound models to SAAP-148 resulted in a 1.5-fold lower LR than for tape-stripped skin. Finally, SAAP148 failed to reduce the bacterial counts in an adapted rat study.

Conclusions: Several factors, such as absorption of SAAP-148 by wound dressings, components within wound exudates, re-colonisation during the exposure of SAAP-148, and a high bacterial load may contribute to the poor antimicrobial effect of SAAP-148 against MRSA in the rat model.

Keywords: Antimicrobial peptides, SAAP-148, Efficacy, Topical therapy, Skin and soft tissue infections, Methicillinresistant Staphylococcus aureus

\footnotetext{
*Correspondence: gdijksteel@burns.nl

${ }^{1}$ Association of Dutch Burn Centres, Zeestraat 29, 1941 AJ Beverwijk, The

Netherlands

Full list of author information is available at the end of the article
} 


\section{Background}

Over the past decades, antibiotic resistance among bacteria has become a global public health problem. The acquisition of nosocomial Methicillin-resistant Staphylococcus aureus (MRSA) by injured patients not only increases the risk of sepsis but also delays wound healing [1-3]. Therefore, the need for alternative therapies that are effective and less likely to cause resistance has increased.

Recently, antimicrobial peptides (AMPs) are being studied as a potential alternative to antibiotics because of their anticipated favourable mechanism of action [4]. It has been demonstrated that AMPs - often small cationic peptides - eradicate a wide range of gram-negative and gram-positive bacteria by disrupting the bacterial membrane [5-7]. Initially, it was believed that AMPs secreted by human skin cells act as a chemical barrier that prevents the invasion of pathogens. However, AMPs display a number of additional functional activities besides their antimicrobial activity. They modulate several inflammatory responses, which in turn influence different cellular processes including wound healing [8-10]. Due to the promising efficacy profile of AMPs, several studies focus on the synthesis of naturally occurring AMPs and on modifications of these naturally occurring AMPs for more effective formulations for the topical treatment of infected or colonised wounds [11].

From a panel of synthetic AMPs, inspired on the structure of the human cathelicidin, LL-37, the synthetic peptide SAAP-148 was selected as the most promising AMP in reduction of bacterial counts [12]. This AMP was found effective against drug-resistant bacteria, persisters and biofilms. More interestingly, SAAP-148 effectively eradicated MSRA in an ex vivo human burn wound model (BWM) and an in vivo tape-stripped mouse model [12]. Subsequently, we studied the efficacy of SAAP-148 in an in vivo partial thickness wound model inoculated with MRSA in rats. Surprisingly, SAAP-148 was not effective in this model and therefore, several possible factors that may have contributed to the poor antimicrobial efficacy of SAAP-148 were identified and studied in in vitro and ex vivo experiments. Based on these experimental results, improvements to the protocol were implemented in a new rat study. The current paper reports on the findings of these in vitro, ex vivo and in vivo experiments.

\section{Methods}

\section{Synthesis and formulation of SAAP-148}

SAAP-148, inspired on LL-37 [13], was synthesised, purified and identified as described by Nell et al. [14]. Lyophilised SAAP-148 was dissolved and diluted in phosphate-buffered saline (PBS; Gibco, Paisley, UK). Aliquots of SAAP-148 in PBS were stored at $-20{ }^{\circ} \mathrm{C}$ until use. Hypromellose (HM) gels with or without SAAP-148 were prepared in two viscosities, i.e. 3:1 (3 parts pre-gel and 1 part peptide solution) and 3:10 (3 parts pre-gel and 10 parts peptide solution), as was previously described by Haisma et al. [15]. HM gels were stored at $4{ }^{\circ} \mathrm{C}$. The SAAP-148 dosages used in the experiments were based on the optimal bactericidal effect of this peptide in the test condition.

\section{Tissue and blood plasma}

Eschar is burned skin tissue that is debrided by a knife during surgery. Eschar and excess tissue that was collected after elective abdominal dermo-lipectomy were obtained under institutional guidelines and following the "code of conduct for responsible use", drafted by Federa (Foundation Federation of Dutch Medical Scientific Societies) from the Red Cross Hospital (Beverwijk, the Netherlands). A dermatome (Aesculap AG \& Co. KG, Tuttlingen, Germany) was used to prepare $0.8 \mathrm{~mm}$ thickness human skin grafts from the abdominal tissue. Rat (Wistar) and mouse (BL/6J) cadavers were purchased from the Amsterdam Animal Research Centre (Amsterdam, the Netherlands). A scalpel was used to collect full-thickness skin grafts from these animal cadavers. Grafts were stored for up to 2 weeks in Roswell Park Memorial Institute (RPMI) 1640 medium, supplemented with $2 \%(\mathrm{v} / \mathrm{v})$ penicillin/streptomycin $(\mathrm{P} / \mathrm{S})(\mathrm{Gibco})$ at $4{ }^{\circ} \mathrm{C}$. Prior to an experiment, the grafts were washed in RPMI 1640 medium at $4{ }^{\circ} \mathrm{C}$ for $24 \mathrm{~h}$ and subsequently in PBS for approximately $2 \mathrm{~h}$ to ensure the removal of P/S. Human blood plasma that was collected from three donors was obtained from Sanquin (Leiden, the Netherlands). The plasma was pooled, centrifuged at $2266 \times g$ for $10 \mathrm{~min}$, filtered using $0.2 \mu \mathrm{m}$ filters to remove aggregates. Aliquots were stored at $-20^{\circ} \mathrm{C}$ until use.

Eschar extracts were prepared by grinding $0.5 \mathrm{~g}$ eschar from three donors separately in $1 \mathrm{~mL}$ of PBS using a 7-mm metal bead and a TissueLyser LT (Qiagen, Venlo, the Netherlands) set at $50 \mathrm{~Hz}$ for $4 \mathrm{~min}$. After centrifugation at $3600 \times g$ for 5 min, the supernatants were pooled. The centrifugation step was repeated at 4200 $\times g$ for $10 \mathrm{~min}$ and the clear eschar supernatant was stored in aliquots at $-20{ }^{\circ} \mathrm{C}$. Skin extracts were prepared by cutting $0.5 \mathrm{~g}$ human skin from three donors into small pieces using a scalpel. Subsequently, the skin parts were grounded separately in $1 \mathrm{~mL}$ of PBS using the protein_01.01 program of the gentleMACS Dissociator (MACS Miltenyi Biotec, Bergisch Gladbac, Germany). After centrifugation at $3820 \times g$ for $15 \mathrm{~min}$, the supernatants were filtered using $0.2 \mu \mathrm{m}$ filters and pooled. This was stored in aliquots at $-20^{\circ} \mathrm{C}$. 


\section{Absorption and/or adsorption of SAAP-148 by wound dressings}

Approximately $1 \mathrm{~cm}^{2}$ of a wound dressing was added to a polypropylene vial containing $100 \mu \mathrm{L}$ of SAAP-148 in PBS $(76 \mathrm{nmol})$. After $1 \mathrm{~h}$ incubation at $37^{\circ} \mathrm{C}$ and $5 \% \mathrm{CO}_{2}$, the wound dressing was removed and the remaining volume of SAAP-148 containing solution was determined using a pipette. The following wound dressings were tested: gauze (BSN Medical GmbH, Hamburg, Germany), Mepilex border (Mölnlycke Health Care AB, Gothenburg, Sweden), Opsite Post-Op (Smith \& Nephew Medical Limited, Hull, UK), Cuticell (BSN Medical GmbH) and Tegaderm film (3 M Health Care, Neuss, Germany). The recovered SAAP-148 containing solutions after incubation with a wound dressing were compared to the same solution without a wound dressing or with a low-adhesive material Parafilm (Merck, KGaA, Darmstadt, Germany), which was used in the in vivo study of de Breij et al. [12].

\section{Bacterial culture}

A clinical isolate of MRSA, strain LUH14616, was stored in Luria-Bertani (LB) broth (Oxoid, Ltd, Basingstoke, UK) medium supplemented with $15 \%$ (v/v) glycerol at $-80{ }^{\circ} \mathrm{C}$. Inoculae were grown on LB agar plates at $37{ }^{\circ} \mathrm{C}$ and $5 \% \mathrm{CO}_{2}$ overnight. To create a mid-log phase growth culture, the bacteria were cultured in LB medium at $37^{\circ} \mathrm{C}$ and $200 \mathrm{rpm}$ for $4 \mathrm{~h}$. After centrifugation at $3600 \times g$ for $5 \mathrm{~min}$, the pellet was re-suspended in PBS to the desired bacterial concentration, estimated by using the optical density at $600 \mathrm{~nm}$.

\section{Processing of samples to quantify viable bacteria}

Samples were homogenised in a TissueLyser set at $50 \mathrm{~Hz}$ for $4 \mathrm{~min}$ using a 7 -mm metal bead. During homogenisation of the samples, sodium polyanethol sulfonate (SPS; Merck $\mathrm{KGaA}$ ) in PBS at a final concentration of $0.05 \%$ $(\mathrm{wt} / \mathrm{v})$ was used to neutralise SAAP-148 and prevent ongoing activity during processing [16]. For the neutralisation of $2 \%$ (wt/wt) mupirocin in an ointment (Bactroban; GlaxoSmithKline B.V., Zeist, the Netherlands) two times the manufacturer's advised concentration of Dey-Engley broth (Merck KGaA) was used [17, 18]. Tenfold serial dilutions of the homogenates were plated on LB agar plates for the in vitro studies, and MRSASelect agar plates (Bio-Rad, Lunteren, the Netherlands) for the animal studies to selectively identify MRSA from commensal bacteria. The number of viable bacteria - colony forming units (CFU) - was quantified after overnight incubation at $37{ }^{\circ} \mathrm{C}$ and $5 \% \mathrm{CO}_{2}$. Results are expressed as the $\log 10$ reduction (LR), which was calculated by subtracting the log number of surviving bacteria after exposure to the peptide from the log number of bacteria in the negative control samples.

\section{In vitro killing assay}

The bacterial suspension was diluted in PBS, human blood plasma, eschar extract or skin extract. $90 \mu \mathrm{L}$ of the bacterial suspension were added to polypropylene vials containing $10 \mu \mathrm{L}$ of SAAP-148 in HM gel, SAAP-148 in PBS, the empty HM gel or PBS. Final mixtures contained $50 \%(\mathrm{v} / \mathrm{v})$ plasma, $50 \%(\mathrm{v} / \mathrm{v})$ eschar extract, $50 \%(\mathrm{v} / \mathrm{v})$ skin extract or PBS only and were briefly vortexed. After incubating the samples at $37{ }^{\circ} \mathrm{C}$ and $5 \% \mathrm{CO}_{2}$ for $30 \mathrm{~min}$, they were processed in $500 \mu \mathrm{L}$ of PBS with drug-neutralisers to quantify the number of viable bacteria.

\section{Preparation of ex vivo models}

Four types of ex vivo models were used: excision wound model, BWM, tape-stripped skin and intact skin. In brief, excision wound models were prepared with a dermatome (width $7 \mathrm{~mm}$ ), which removed $0.3 \mathrm{~mm}$ of the upper part of the skin graft containing the epidermis. Subsequently, the graft was cut into pieces of $1 \mathrm{~cm}^{2}$ using a scalpel. BWMs were prepared by wounding $1 \mathrm{~cm}^{2}$ skin thermally with a soldering iron $(10 \times 2 \mathrm{~mm})$ set at $95{ }^{\circ} \mathrm{C}$ for $10 \mathrm{~s}$ [19]. The tape-stripped skin was prepared by stripping the graft 20 times (replacing the tape after each time) using Tensoplast (BSN Medical GmbH) [12]. Afterward, the tape-stripped graft was cut into pieces of $1 \mathrm{~cm}^{2}$. Intact skin models were prepared by cutting the skin graft into pieces of $1 \mathrm{~cm}^{2}$.

\section{Infection and treatment of ex vivo skin}

Ex vivo models were inoculated with $10 \mu \mathrm{L}$ of MRSA and treated with SAAP-148 in HM gel, SAAP-148 in PBS, wound dressings containing SAAP-148, the empty HM gel or PBS at $37{ }^{\circ} \mathrm{C}$ and $5 \% \mathrm{CO}_{2}$. The samples were processed in $1 \mathrm{~mL}$ of PBS with drug-neutralisers to quantify the number of viable bacteria.

\section{Efficacy of SAAP-148 in a rat model}

Immune competent male and female rats (Wistar) of 8 to 10 weeks old with a minimum weight of $160 \mathrm{~g}$ were purchased from Envigo (Horst, the Netherlands). These animals were kept under specific pathogen-free conditions and were housed in individually ventilated cages. Woodshavings were used as bedding material and long paper strips as enrichment. The rats were provided with tap water and an irradiated-sterilised pelleted diet ad libitum.

The sample size was calculated with data of in vitro studies and literature [20]. The type I error probability was set at 0.05 . To identify a 140 -fold decrease in bacterial counts and assuming a standard deviation (SD) of 80, a sample size of 5 per group (with a power of 0.8 ) was required. Considering the possibility of ${ }^{<} 10 \%$ drop-out, a sample size of 6 per group per treatment time was used. To minimize the number of experimental animals two 
wounds, one on each flank, were prepared on the back of the rats. Six groups, each with one wound on 6 male and 6 female rats were used.

The MRSA inoculated wounds were treated with 306 (group 1) or $612 \mathrm{nmol}$ (group 2) SAAP-148 in 3:10 HM gel, 153 (group 3) or $306 \mathrm{nmol}$ (group 4) SAAP148 in PBS, the empty HM gel (group 5) or $2 \%$ (wt/wt) Bactroban (group 6) (see Additional file 1: Table S1 for SAAP-148 dosages in percentages). A lower dosage of SAAP-148 in PBS was used to prevent possible toxicity effects caused by the instantaneous high availability of the peptide in the wounds. Four h or $24 \mathrm{~h}$ after treatment, six wounds (i.e. one wound on 3 male and 3 female rats) of each group were sampled.

Thirty to sixty minutes pre-operative, 36 rats were subcutaneously injected with analgesic Temgesic $(1 \mu \mathrm{g} / 100 \mathrm{~g})$ and were given tap water containing Temgesic $(0.01 \mathrm{mg} /$ $\mathrm{kg}$ ) for $24 \mathrm{~h}$ to reduce post-operative pain. Additionally, $1-2 \mathrm{~h}$ pre-operatively the rats were subcutaneously injected with Carprofen $(5 \mathrm{mg} / \mathrm{kg}$ ) to reduce pain and fever. During the interventions, the rats were kept under anesthesia with $2 \%$ isoflurane in oxygen. To maintain the body temperature a heated pad was used. The back of the rats was shaved using an electric razor and the remaining hair was removed using Veet hair removal cream for sensitive skin (RB Health Care, Hoofddorp, the Netherlands). The skin was disinfected with $70 \%$ alcohol and sprayed with analgesic $1 \%$ Lidocaine to locally anesthetize the skin. Two excision wounds of approximately $1 \mathrm{~cm}^{2}$ were created on the back of the rats with a dermatome set at $0.8 \mathrm{~mm}$. To confirm sterility, the wounds were swabbed using forensic swabs (Sarstedt AG \& Co, Nümbredt, Germany) soaked in sterile PBS. Subsequently, the wounds were inoculated by placing gauze containing $100 \mu \mathrm{L}$ of $10^{8} \mathrm{CFU} / \mathrm{mL}$ MRSA on the wound, which was kept in place with a self-adhesive wound dressing Petflex (3 M Health Care) and a Leukosilk plaster (BSN Medical $\mathrm{GmbH}$ ) around the entire trunk. Post-operative, the rats received a subcutaneous injection with analgesic Metacam $(1 \mathrm{mg} / 100 \mathrm{~g})$ to further reduce pain. After overnight inoculation, the wounds were wiped three times using a PBS-moist gauze, similar to human clinical protocols. Then the wounds were swabbed to determine the starting bacterial load. They were topically treated with $100 \mu \mathrm{L}$ of 306 or $612 \mathrm{nmol}$ SAAP-148 in 3:10 HM gel, 153 or 306 nmol SAAP-148 in PBS, the empty HM gel (negative control) or $2 \%$ (wt/wt) Bactroban (positive control). The wounds were covered with Tegaderm film followed by Petflex and a Leukosilk plaster. After $4 \mathrm{~h}$ and $24 \mathrm{~h}$ treatment, the rats were euthanised using saturated $\mathrm{CO}_{2} / \mathrm{O}_{2}$ followed by $\mathrm{CO}_{2}$ only. Subsequently, the number of superficially located bacteria in the wounds were determined using swabs and those within the tissue were determined using $4 \mathrm{~mm}$ punch biopsies. Samples were processed in $1 \mathrm{~mL}$ of PBS with drug-neutralisers to determine the number of surviving bacteria.

\section{Statistical analysis}

To determine the statistically significant differences between two sample groups the non-parametric Kruskal-Wallis test and the Mann-Whitney rank sum test were used. For comparison of two time points, the Wilcoxon signed-rank test was used. $\mathrm{p}$-values $\leq 0.05$ were considered statistically significant.

\section{Results}

In a previous experiment, SAAP-148 in 3:1 HM gel failed to cause a significant $\mathrm{LR}$, despite repetitive daily administration of SAAP-148 to these wounds (Additional file 1: Figure S1). Therefore, we performed additional in vitro and ex vivo experiments to determine some of the possible factors contributing to this poor antimicrobial effect of SAAP-148, such as formulation in HM gel, absorption and/or adsorption of SAAP-148 by wound dressings, exposure periods of SAAP-148, bacterial loads and components in the wound micro-environment. Subsequently, we optimised the in vivo protocol and assessed the efficacy of SAAP-148 in an adapted rat study.

\section{The viscosity of $\mathrm{HM}$ gel affects the bactericidal efficacy of SAAP-148}

To exclude the possibility that SAAP-148 was unable to exert its antimicrobial effect because it remained in the viscous 3:1 $\mathrm{HM}$ gel and did not reach the bacteria in the wound, we explored an alternative viscosity of the HM gel to potentially improve the release of the peptide from the HM gel and thus its bactericidal effect. We assessed the effect of vortex mixing on the efficacy of SAAP-148 (7.6 nmol) in $3: 1$ or $3: 10 \mathrm{HM}$ gel using in vitro killing assays. The results revealed that increasing the vortex mixing period from 0 to $30 \mathrm{~s}$ resulted in a 2 -fold $(\mathrm{p}<0.01)$ higher LR for SAAP-148 in 3:1 HM, whereas for SAAP148 in 3:10 $\mathrm{HM}$ gel the LR at $0 \mathrm{~s}$ was already high and comparable to the LR at $30 \mathrm{~s}$. Additionally, the LR caused by SAAP-148 in 3:10 HM gel was $1.5(\mathrm{p}<0.01)$ and 1.3fold $(\mathrm{p}<0.05)$ higher than for SAAP-148 in 3:1 HM gel at vortex mixing periods of $5 \mathrm{~s}$ and $20 \mathrm{~s}$, respectively (Fig. 1a).

Furthermore, we compared the efficacy of SAAP-148 in 3:1 and 3:10 $\mathrm{HM}$ gel using ex vivo excision wound models. The ex vivo models were inoculated for $4 \mathrm{~h}$ with approximately $10^{5} \mathrm{CFU} / \mathrm{mL}$ MRSA and exposed to $50 \mu \mathrm{L}$ of SAAP-148 in 3:1 or 3:10 HM gels or the empty HM gel for $1 \mathrm{~h}$. Although we could not establish significant differences in the bactericidal efficacy of SAAP-148 in 3:10 versus 3:1 $\mathrm{HM}$ gel, the LR after exposure to SAAP-148 in 
a

Effect of the vortex mixing period on the Log10 reduction of MRSA by SAAP-148 in varying viscosities of HM gel

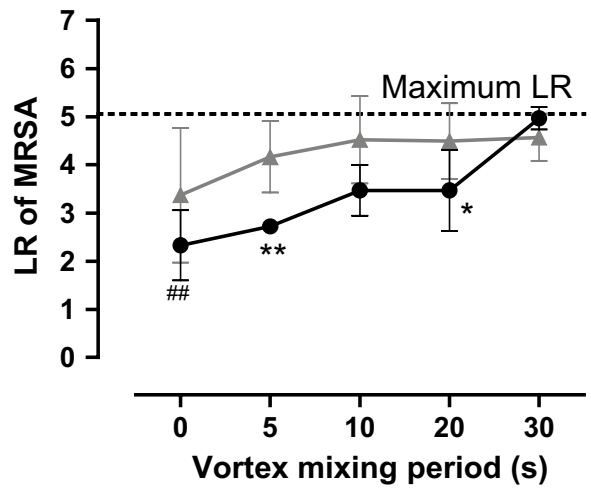

- $3: 1 \mathrm{HM}$

- 3:10 HM b

Log10 reduction of MRSA by SAAP-148 in varying viscosities of HM gel

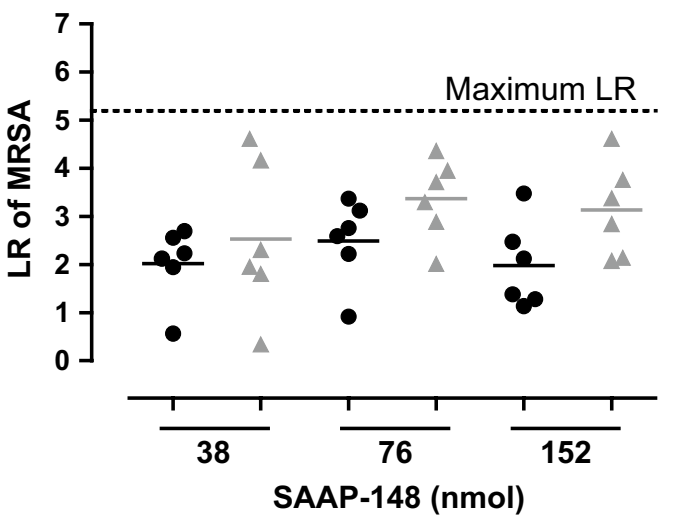

Fig. 1 Efficacy of SAAP-148 formulated in HM gels. a In vitro killing of $10^{5}$ CFU/mL MRSA by $7.6 \mathrm{nmol}$ SAAP-148 in 3:1 or 3:10 HM gel or the empty HM gel as negative control. The mixtures were either vortexed or not. The vortex mixing period is indicated on the $x$-axis. The mean \pm SD of six experiments performed in duplicate is shown. " indicates significant difference compared to the LR at $30 \mathrm{~s}(\# \#)<0.01$ ) and * indicates significant difference $\left({ }^{*} p<0.05 ;{ }^{* *} p<0.01\right)$ compared to SAAP-148 in 3:10 HM. b The ex vivo efficacy of SAAP-148 in 3:1 or 3:10 HM gels. Excision wound models were inoculated with approximately $10^{5} \mathrm{CFU}$ for $4 \mathrm{~h}$ and exposed to $50 \mu \mathrm{L}$ of 3:1 or 3:10 HM gels containing $38 \mathrm{nmol}, 76 \mathrm{nmol}, 152 \mathrm{nmol}$ SAAP-148 or the empty HM gel (negative control) for $1 \mathrm{~h}$. The mean of six independent experiments performed in triplicate is shown. Results are expressed as the LR

3:10 HM gel seemed greater, especially at high dosages (Fig. 1b).

Overall, SAAP-148 in the 3:1 HM gel caused a lower LR as compared to SAAP-148 in the 3:10 HM gel. Therefore, the following experiments were performed with SAAP148 in 3:10 HM gel or in PBS to assure the most optimal availability of the peptide to interact with bacteria.

\section{Effect of wound dressings on the efficacy of SAAP-148}

In the pilot rat study gauze and Cuticell were used as wound dressings for the excision wounds (Additional file 1: Information). Absorption and/or adsorption of the SAAP-148 treatment by gauze and Cuticell might have contributed to the poor antimicrobial efficacy of SAAP-148 in vivo. Therefore, we determined the amount of peptide solution that could be recovered after $1 \mathrm{~h}$ incubation of $100 \mu \mathrm{L}$ of SAAP-148 in PBS (76 nmol) with $1 \mathrm{~cm}^{2}$ of different wound dressings or a low adhesive material Parafilm. Compared to the control samples without a wound dressing, $<20 \%$ of the peptide solution was recovered after incubation with gauze, Mepilex border or Opsite Post-Op. In contrast, $45 \%, 56 \%$ and $75 \%$ of the peptide solution were recovered after incubation with Cuticell, Parafilm or Tegaderm film, respectively (Fig. 2a). Therefore, we then investigated the in vitro efficacy of only the SAAP-148 solutions that were recovered after incubation with Cuticell, Parafilm or Tegaderm film and determined if the presence of these wound dressings affected the antimicrobial activity of SAAP-148 against MRSA. Ten $\mu \mathrm{L}$ of the recovered SAAP-148 solution that had been incubated in the presence of Cuticell caused a 1.3-fold $(\mathrm{p}<0.05)$ lower mean LR than SAAP-148 that was not incubated in the presence of a wound dressing (positive control) or SAAP-148 that was incubated in the presence of Parafilm (Fig. 2b). Thus, the presence of Cuticell, which is a moist silicon wound contact layer, negatively affected the antimicrobial activity of SAAP-148. On the contrary, the presence of Parafilm or Tegaderm film in the peptide solutions did not have a significant effect on the antimicrobial activity of SAAP-148 against MRSA.

Next, we evaluated whether SAAP-148 that was absorbed and/or adsorbed by the different wound dressings or Parafilm could still be released to eradicate bacteria. Ex vivo excision wound models were inoculated with $10^{5} \mathrm{CFU} / \mathrm{mL}$ MRSA for $1 \mathrm{~h}$ and exposed to a wound dressing containing $15 \mathrm{nmol}$ SAAP-148, $20 \mu \mathrm{L}$ of SAAP-148 in PBS (15 nmol) (positive control) or PBS (negative control) for $1 \mathrm{~h}$. Results showed that all the tested wound dressings containing SAAP148 caused a mean LR that was 2.3 -fold $(\mathrm{p}<0.05)$ or $>$ 4-fold ( $\mathrm{p}<0.01$ ) lower than for SAAP-148 in PBS (positive control) (Fig. 3). This suggests that SAAP-148 was 
a

\section{In vitro recovery of SAAP-148 \\ after incubation with wound dressings}

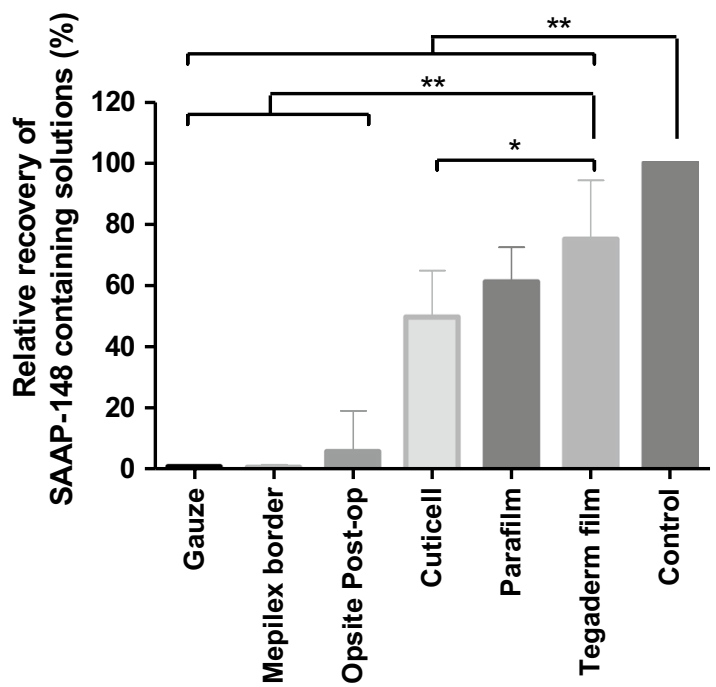

b

Log10 reduction of MRSA by

SAAP-148 that was recovered

after incubation with wound dressings

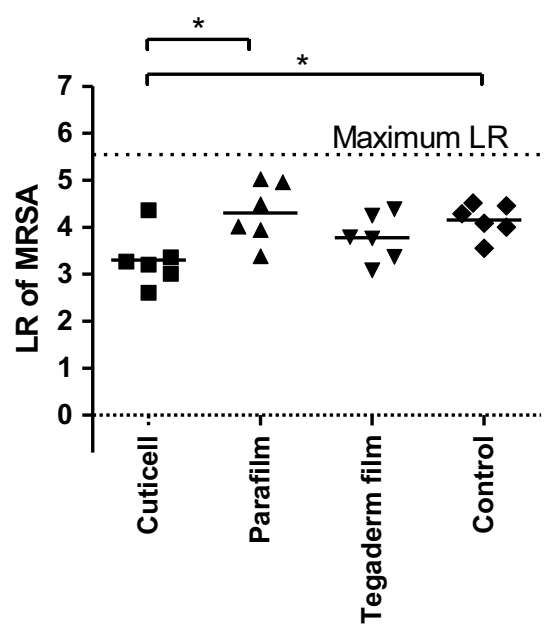

Fig. 2 Absorption and/or adsorption by wound dressings and its effect on the efficacy of SAAP-148. a $100 \mu \mathrm{L}$ of SAAP-148 in PBS (76 nmol) were incubated with or without $1 \mathrm{~cm}^{2}$ of a wound dressing or low adhesive Parafilm for 1 h. Subsequently, the remaining volume of SAAP-148 containing solutions were determined. Results are expressed as the relative recovery of the solutions in percentages of control samples without a wound dressing. Data are shown as mean \pm SD of six independent experiments. $\mathbf{b}$ In vitro killing of MRSA by $10 \mu \mathrm{L}$ of SAAP-148 containing solutions that were remaining after incubation with or without Cuticell, Parafilm and Tegaderm film. PBS was used as negative control. Results are expressed as the LR. The mean of six independent experiments performed in triplicate is shown. ${ }^{*}$ indicates significant difference $\left({ }^{*} \mathrm{p}<0.05\right.$; $\left.{ }^{* *} \mathrm{p}<0.01\right)$ compared to control samples

not sufficiently released from these wound dressings to eradicate MRSA on ex vivo skin.

In summary, Tegaderm film is a more appropriate wound dressing than gauze or Cuticell because it is less likely to absorb the peptide or affect its antimicrobial activity.

\section{Exposure of MRSA infected skin models to SAAP-148 for $1 \mathrm{~h}, 4 \mathrm{~h}$ or $24 \mathrm{~h}$}

To establish the efficacy of SAAP-148 over time, ex vivo excision wound models were inoculated with $10^{5} \mathrm{CFU}$ MRSA for $1 \mathrm{~h}$ and exposed to $20 \mu \mathrm{L}$ of SAAP-148 in PBS (60 nmol) or PBS (negative control). After $1 \mathrm{~h}, 4 \mathrm{~h}$ or $24 \mathrm{~h}$, the mean LR caused by SAAP-148 was determined. Exposure of the models to SAAP-148 for $1 \mathrm{~h}$ or $4 \mathrm{~h}$ resulted in a LR of 3.5 and 3.6, respectively. However, exposure of the models to SAAP-148 for $24 \mathrm{~h}$ resulted in a mean LR of only 0.9 , which was significantly $(\mathrm{p}<0.01)$ lower than the LR caused by SAAP-148 after a $1 \mathrm{~h}$ or $4 \mathrm{~h}$ exposure period (Fig. 4 ). Thus, SAAP148 is effective against MRSA after $1 \mathrm{~h}$ or $4 \mathrm{~h}$ but not after $24 \mathrm{~h}$, indicating that the peptide should be applied multiple times a day.

\section{SAAP-148's efficacy in relation to bacterial load}

The relatively high bacterial load $\left(10^{7} \mathrm{CFU} /\right.$ wound $)$ in the excision wounds of the rat model might have contributed to the poor antimicrobial effect of SAAP-148 in the pilot study (Additional file 1: Information). To evaluate this, in vitro killing assays were performed where $10^{3}, 10^{5}, 10^{6}$ or $10^{7} \mathrm{CFU}$ MRSA were exposed to $10 \mu \mathrm{L}$ of SAAP-148 in PBS (7.6 nmol) or PBS (negative control). SAAP-148 eradicated an absolute higher number of bacteria as the bacterial load increased from $10^{3} \mathrm{CFU}$ to $10^{7} \mathrm{CFU}$. However, SAAP-148 caused a 1.3 -fold $(\mathrm{p}<0.05)$ lower mean LR at a bacterial load of $10^{7} \mathrm{CFU}$ than at $10^{6}$ or $10^{5} \mathrm{CFU}$ MRSA (Fig. 5a). The same was found for ex vivo excision wound models (Fig. 5b). Notably, the mean LR caused by SAAP-148 was 1.3 to 1.5 -fold $(\mathrm{p}<0.01)$ lower in the presence of ex vivo skin at a bacterial load of $10^{6}$ or $10^{5} \mathrm{CFU}$ MRSA. Thus, SAAP-148 is less effective against high bacterial loads of $10^{7}$ CFU MRSA, which was used in the in vivo rat study.

\section{In vitro activity of SAAP-148 in plasma, eschar or skin extract}

To determine the efficacy of SAAP-148 in biologically relevant conditions, we performed additional in vitro 


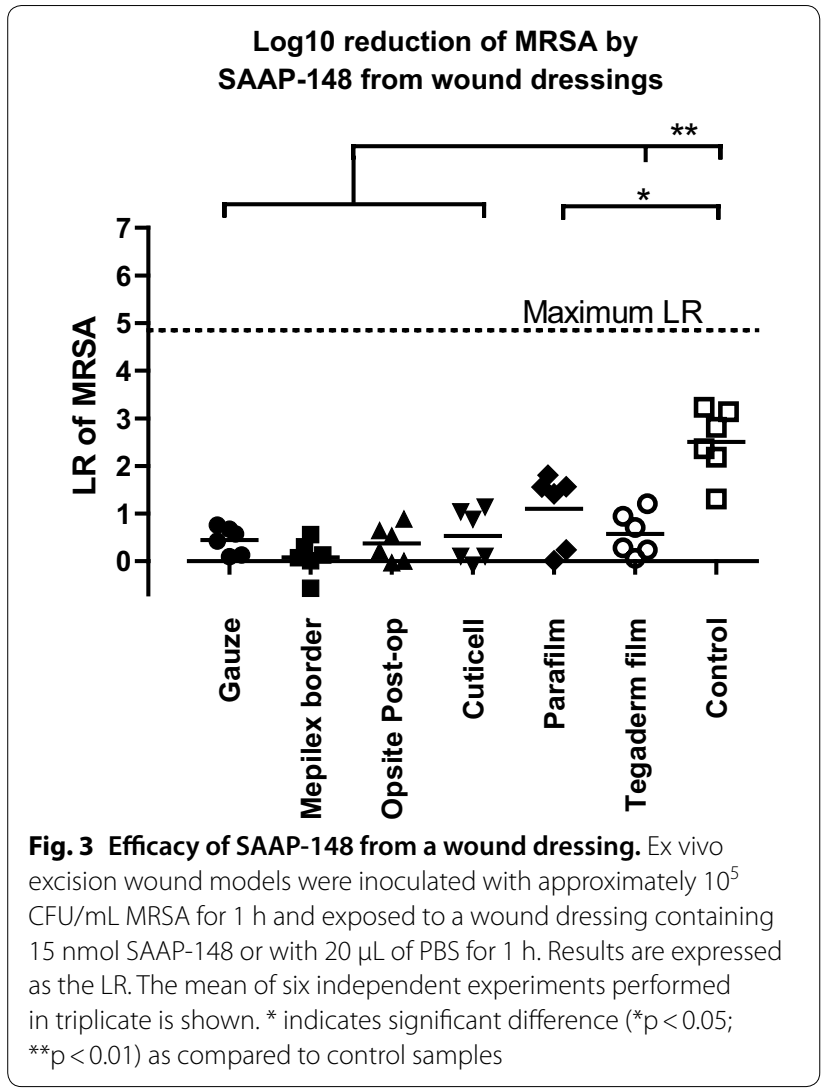

killing assays in PBS with 50\% (v/v) plasma, 50\% (v/v) eschar extract or $50 \%(\mathrm{v} / \mathrm{v})$ skin extract. In these conditions, SAAP-148 eradicated MRSA in a dose-dependent manner. However, higher dosages of SAAP-148 were required to achieve a $2-\mathrm{LR}$ in $50 \%(\mathrm{v} / \mathrm{v})$ plasma, $50 \%(\mathrm{v} / \mathrm{v})$ eschar extract or $50 \%(\mathrm{v} / \mathrm{v})$ skin extract than in PBS, i.e.: $2.3 \mathrm{nmol}, 3.1 \mathrm{nmol}, 2.8 \mathrm{nmol}$ and $0.1 \mathrm{nmol}$, respectively. Strikingly, even at the highest peptide dosage of $30 \mathrm{nmol}$, still approximately $10^{2} \mathrm{CFU} / \mathrm{mL}$ MRSA survived in all of these conditions (Fig. 6).

Efficacy of SAAP-148 against MRSA in different skin models Because the earlier animal experiments of SAAP-148 were performed using a tape stripped mouse model [12], we evaluated the efficacy of SAAP-148 in different environments using ex vivo skin models. The models were inoculated with approximately $10^{5} \mathrm{CFU} / \mathrm{mL}$ MRSA and after $1 \mathrm{~h}$ they were exposed to $20 \mu \mathrm{L}$ of SAAP-148 in PBS $(60 \mathrm{nmol})$ or PBS (negative control) for $1 \mathrm{~h}$.

First, we evaluated the efficacy of SAAP-148 in four types of ex vivo models prepared from human skin, i.e. the excision wound model, BWM, tape-stripped skin and intact skin. The LR caused by SAAP-148 varied among the different models. However, SAAP-148 caused a

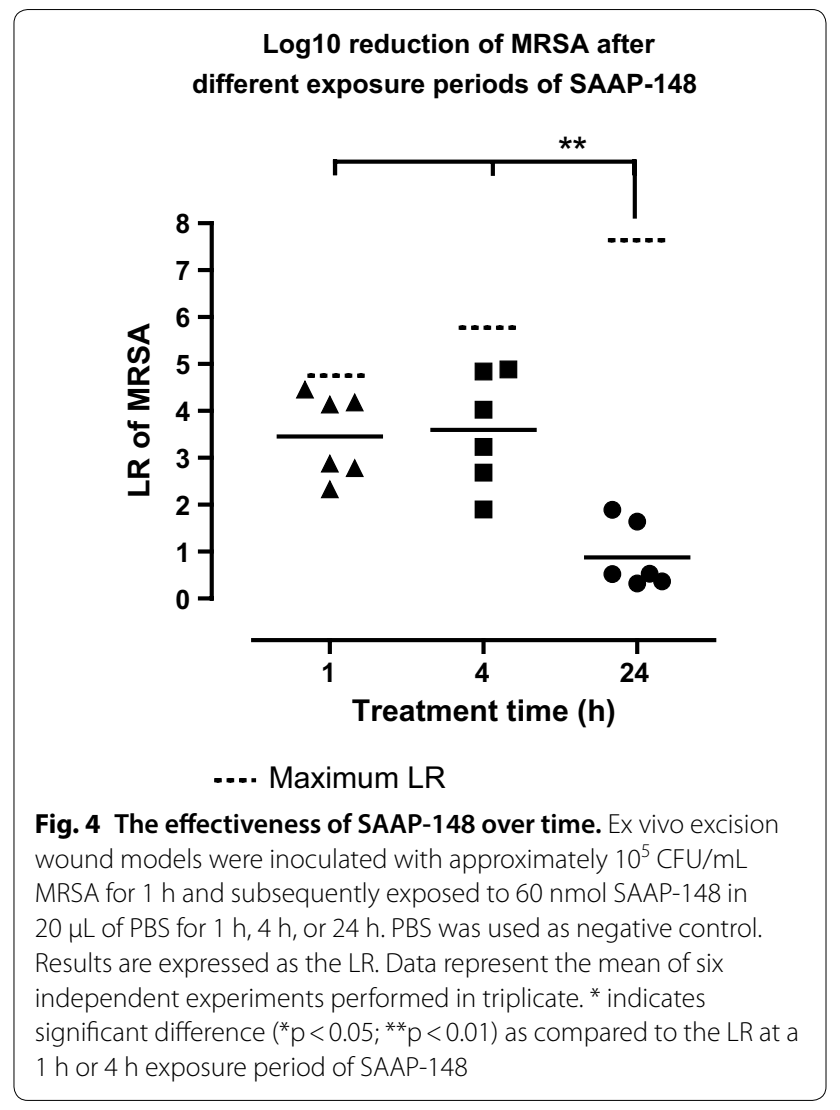

1.5 -fold lower $(\mathrm{p}<0.05)$ mean LR in the excision wound models than on tape-stripped skin (Fig. 7a).

Next, we determined the efficacy of SAAP-148 using ex vivo BWMs prepared from skin of three species, i.e. human, rat and mouse. SAAP-148 caused a comparable mean LR in the BWMs of these different species (Fig. 7b). Significant differences were not noted.

Thus, SAAP-148 is less effective against MRSA in excision wound models than on tape-stripped skin and its potency is independent of the skin characteristics from the tested species.

\section{SAAP-148 treatment in a rat model}

Based on the results above, we adapted the protocol for the study of the efficacy of SAAP-148 in MRSA-inoculated excision wounds in rats. The wounds on the back of 36 rats were inoculated with $100 \mu \mathrm{L}$ of $10^{8} \mathrm{CFU} / \mathrm{mL}$ MRSA and after $24 \mathrm{~h}$ (immediately before the treatment), the wound-swabs showed bacterial counts of approximately $10^{6} \mathrm{CFU} /$ wound. The wounds were topically treated with $100 \mu \mathrm{L}$ of 306 or $612 \mathrm{nmol} \mathrm{SAAP-148}$ in 3:10 HM gel, 153 or 306 nmol SAAP-148 in PBS, the empty $\mathrm{HM}$ gel (negative control) or $2 \%(\mathrm{wt} / \mathrm{wt}$ ) Bactroban (positive control). Treatment with SAAP-148 or Bactroban for $4 \mathrm{~h}$ or $24 \mathrm{~h}$ did not eradicate a significant number 
a

Log10 reduction of different bacterial loads MRSA by SAAP-148 in vitro

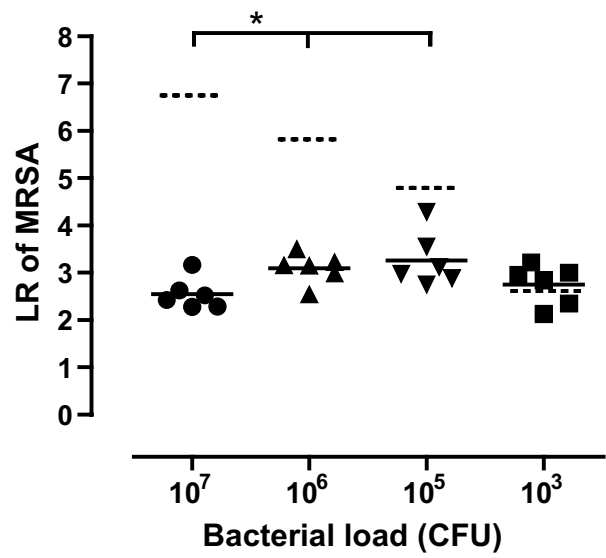

b Log10 reduction of different bacterial loads MRSA by SAAP-148 ex vivo

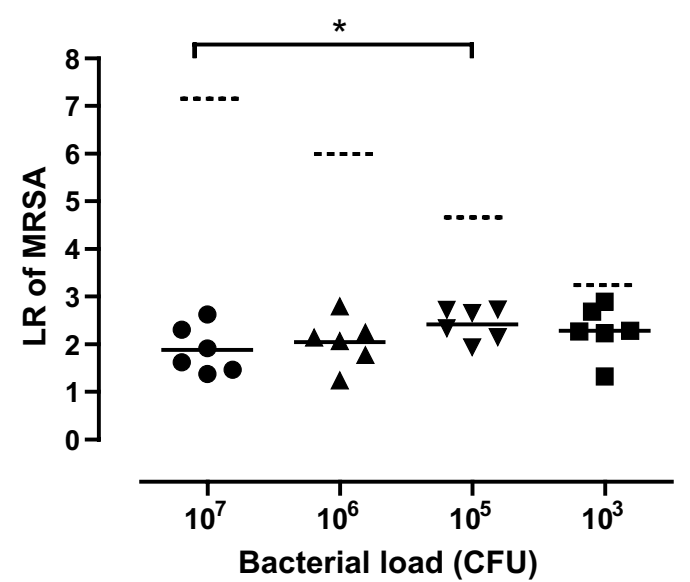

--.- Maximum LR

Fig. 5 SAAP-148 against different bacterial loads of MRSA. The effect of $7.6 \mathrm{nmol}$ SAAP-148 in PBS on different bacterial loads. a In vitro killing of $10^{3}, 10^{5}, 10^{6}$ or $10^{7}$ CFU MRSA by $10 \mu \mathrm{L}$ of PBS or SAAP-148 in PBS after 30 min incubation. $\mathbf{b}$ Ex vivo excision wounds were inoculated with $10^{3}$, $10^{5}, 10^{6}$ or $10^{7} \mathrm{CFU}$ MRSA for $1 \mathrm{~h}$ and exposed to $10 \mu \mathrm{L}$ of SAAP-148 in PBS or PBS for $1 \mathrm{~h}$. Results are expressed as the LR. Data represent the mean of six independent experiments performed in triplicate. ${ }^{*}$ indicates significant difference $\left({ }^{*} \mathrm{p}<0.05 ;{ }^{* *} \mathrm{p}<0.01\right)$ as compared to the LR caused by SAAP- 148 at $10^{7}$ CFU MRSA

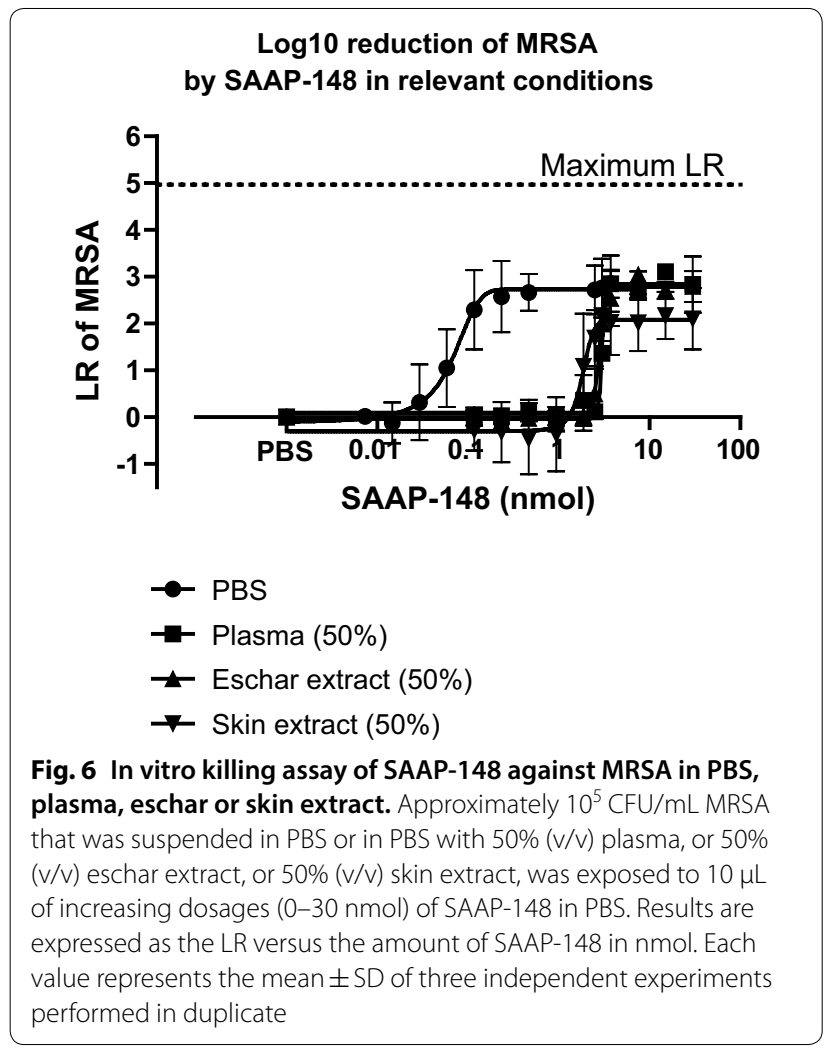

of MRSA as compared to the negative control. Also, the mean bacterial counts of all SAAP-148-treated wounds were $>2$-fold $(\mathrm{p}<0.05)$ higher than that of the negativeand positive control after $24 \mathrm{~h}$ treatment, resulting in a negative LR in Fig. 8c, d.

\section{Discussion}

The aim of the current study is to investigate the poor antimicrobial effect of a novel AMP, SAAP-148, against MRSA in excision wounds in vivo. In our pilot rat study (Additional file 1: Figure S1), SAAP-148 failed to reduce the bacterial counts in the wounds, which was an unexpected finding in view of the previous in vitro and in vivo studies with SAAP-148 [12]. Therefore, we focused on identifying some of the potential factors contributing to the poor antimicrobial effect of SAAP-148 in this model. We tested the HM gel formulation, absorption and/or adsorption of SAAP-148 by wound dressings, exposure periods of SAAP-148, bacterial loads and components in the wound micro-environment. Most of the tested aspects negatively influenced the bactericidal effect of SAAP-148 to varying degrees and the conditions with the most optimal bactericidal effect of SAAP-148 were used in the adapted rat study. 
a

Log10 reduction of MRSA by SAAP-148 in four types of models

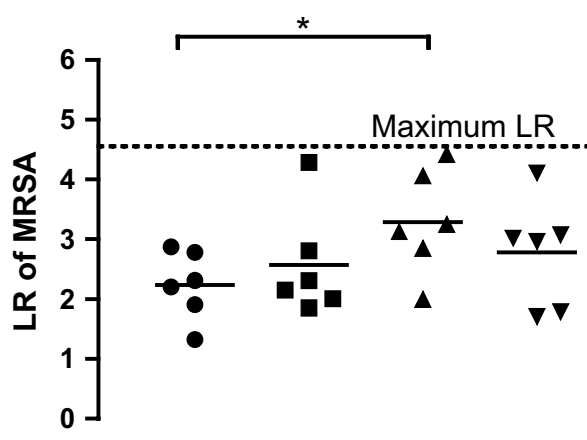

b

Log10 reduction of MRSA by SAAP-148 in BWMs of skin from three species

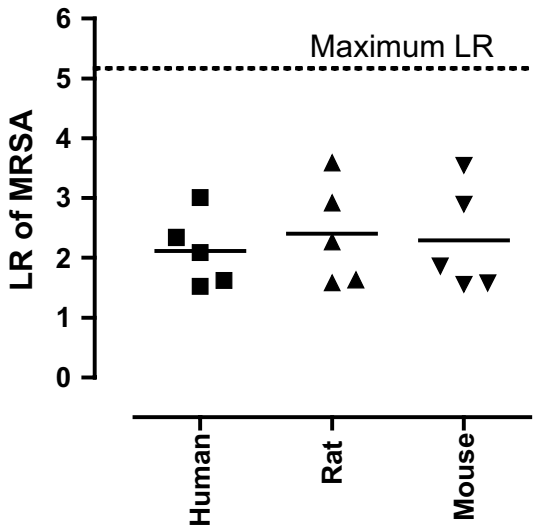

Fig. 7 Antimicrobial activity of SAAP-148 against MRSA in different ex vivo models. Ex vivo models were inoculated with approximately $10^{5}$ $\mathrm{CFU} / \mathrm{mL}$ MRSA for $1 \mathrm{~h}$ and then exposed to $20 \mathrm{\mu L}$ of PBS with or without $60 \mathrm{nmol}$ SAAP-148 in PBS for $1 \mathrm{~h}$. a The efficacy of SAAP-148 in four wound types, i.e. excision wounds, BWM, tape-stripped skin and intact. $\mathbf{b}$ The efficacy of SAAP-148 in BWMs of skin from three species, i.e. human, rat and mouse. Results are expressed as the LR. Data represent the mean of at least five independent experiments performed in triplicate. * indicates significant difference $\left({ }^{*} p<0.05 ;{ }^{* *} p<0.01\right)$

Despite all the adjustments to improve the in vivo protocol and the performance of SAAP-148, this peptide failed to cause a significant LR as compared to the negative control (HM gel) (Fig. 8). Absorption by the wound dressing, gauze, was probably a major factor contributing to the poor antimicrobial effect of SAAP-148 in the pilot rat study but not in the adapted rat study, where the non-absorbing Tegaderm film was used. In this study, the wound environment played the major part in the failure of SAAP-148. We found that at least 20-fold higher dosages of SAAP-148 were required to eradicate MRSA effectively, especially in the presence of ex vivo skin (Fig. 5), 50\% (v/v) plasma, 50\% (v/v) eschar extract or 50\% (v/v) skin extract (Fig. 6). Previously, a similar impact of a protein-rich environment on the efficacy of antimicrobial agents was reported. The presence of proteases, human dentin, plasma proteins including albumin and lipoproteins such as high-density lipoprotein, and lipopolysaccharide inhibited the antimicrobial activity of the tested antimicrobial agents [12, 21-25]. This suggests a reduced availability of antimicrobials to interact with bacteria as a result of protein binding and/or proteolytic degradation. It complicates the therapeutic application of SAAP148 for excision wounds, which consist of a protein-rich environment.
Moreover, increasing the peptide dosages did not result in the complete elimination of the bacteria in the adapted rat study but also not in the in vitro and ex vivo experiments, which could be explained by $i$ ) the presence of bacterial aggregates that may form biofilms and ii) persistent bacteria as described by Bay et al. [26]. This is in contrasts to the findings of de Breij et al. who reported that SAAP-148 is effective against biofilms and eradicates persistent bacteria [12]. The differences in results might be due to the higher susceptibility of the $S$. aureus strain JAR060131 or due to limited protein presence in the tape-stripped mouse model that was used in their study. To elaborate, SAAP-148 eradicated a comparable number of bacteria in ex vivo models with skin from different species (Fig. 7b) but SAAP-148 caused a 1.5-fold lower $(\mathrm{p}<0.05)$ mean LR in the excision wounds than on tape-stripped skin (Fig. 7a). Taking into consideration that deep acute wounds more likely consist of a proteinrich environment (plasma and exudate), the efficacy differences of SAAP-148 between superficial and partial thickness acute wounds might be even larger clinically. Of note, the absence of a drug-neutraliser for SAAP-148 after sampling in the study of de Breij et al. could have resulted in an extended exposure of SAAP-148 to the bacteria. This could have resulted in the eradication of 
$4 \mathrm{~h}$ Treatment
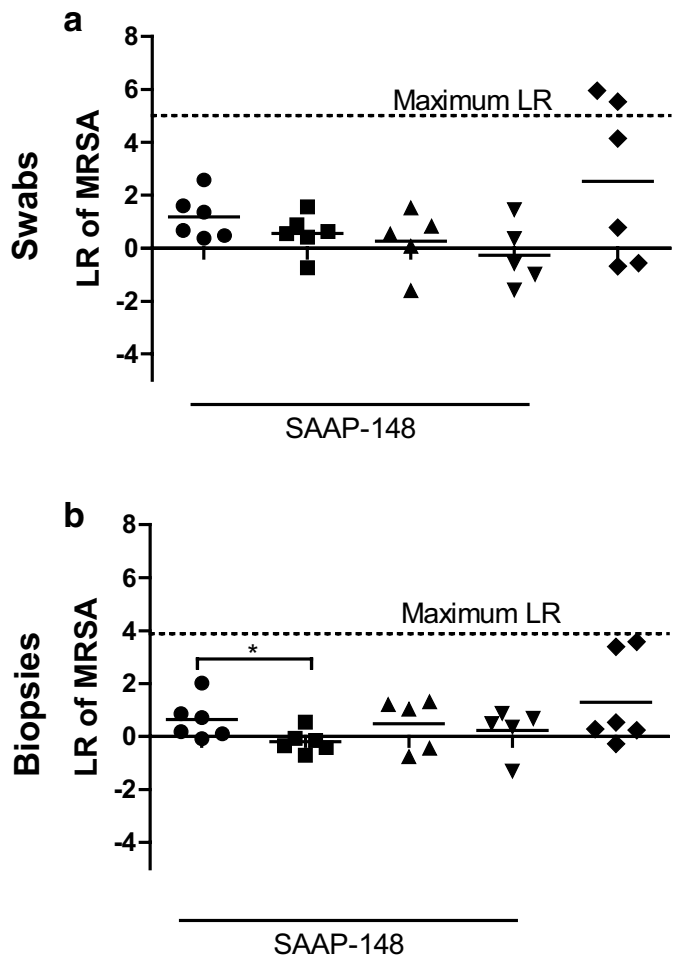

$24 \mathrm{~h}$ Treatment

c

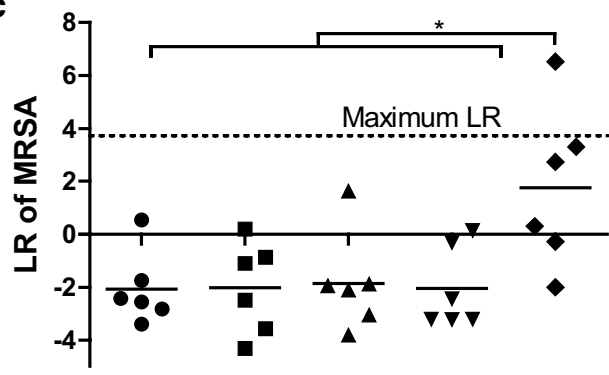

SAAP-148

d

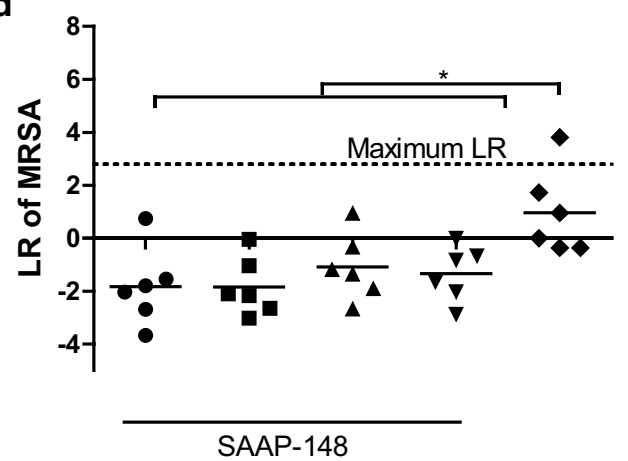

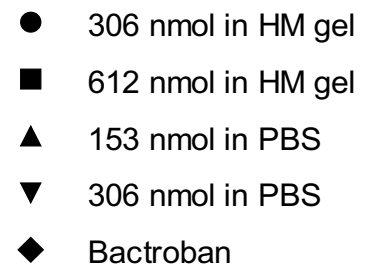

Fig. 8 Efficacy of SAAP-148 in a rat model. The bacterial load of excision wounds from rats was determined using swabs (A/C) and punch biopsies (b, d) of the wounds. After an overnight inoculation with MRSA, the wounds were treated for $4 \mathrm{~h}(\mathbf{a}, \mathbf{b})$ or $24 \mathrm{~h}(\mathbf{c}, \mathbf{d})$ with $100 \mu \mathrm{L}$ of $3: 10$ HM gel containing 306 or 612 nmol SAAP-148 or PBS containing 153 or 306 nmol SAAP-148 or the empty HM gel (negative control) or 2\% (wt/ wt) Bactroban (positive control). Results are expressed as the LR. Data represent the mean of at least five samples. * indicates significant difference $\left({ }^{*} p<0.05 ;{ }^{* *} p<0.01\right)$

surviving bacteria after sampling the wounds and thus only an apparent effective eradication of bacteria in the wound [16].

The need for high treatment dosages to completely eliminate bacteria in vivo has been emphasised by Tsai et al. who topically exposed bacteria to $>1000$ times the minimum inhibitory concentration of gentamicin or minocycline to assure an effective bacterial elimination [27]. However, high antimicrobial dosages may result in adverse effects. Alternatively, optimising the peptide formulation to cause a burst release upon the presence of bacterial proteins, could result in a selective and complete elimination of bacteria. Such a phenomenon was previously shown for Prodrugs, whereby the active AMP is released upon degradation of the protease-sensitive peptide, which was bound to the positively charged group of the AMP for protection [28]. Enzymes, such as betalactamase can break down the protecting peptide, which in turn results in high availability of the active AMP to eradicate bacteria completely [28].

The importance of eradicating bacteria completely is supported by the results obtained from our ex vivo experiment using excision wound models and different exposure periods of SAAP-148 (Fig. 4). The results indicated that SAAP-148 is effective within the first few hours but that bacteria that survived are able to proliferate and 
re-colonise the wounds. This might have been the case in our pilot rat study, where the efficacy of SAAP-148 was only studied after $24 \mathrm{~h}$ treatment (Additional file 1 : Information). Accordingly, Müsken et al. reported that the time required for surviving bacteria to repopulate the biofilm could be taken as a measure for the effectiveness of the antimicrobial treatment and that this is also dependent on the duration of antibiotic treatment and interval of drug administration [29]. This suggests that repeated dosing of SAAP-148 would be required after short treatment times to effectively eradicate bacteria. However, a short treatment time of $1 \mathrm{~h}$ or $4 \mathrm{~h}$ is not preferable in clinical settings because of the high workload for medical personnel but also for the burden to the patient [30,31]. Possibly, a continuous and sustained release of the peptide during a $24 \mathrm{~h}$ treatment could eradicate bacteria effectively without causing adverse effects. Previously, such functionalised wound dressings have been prepared for several antimicrobial agents and have shown to be effective [32-34]. However, MRSA was not effectively eradicated in our ex vivo experiment, where colonised ex vivo excision wounds had been exposed to wound dressings containing SAAP-148. This suggests that SAAP-148 was not sufficiently released from the wound dressings to eradicate bacteria (Fig. 3). Hence, more work focussing on the release profile is needed to develop a functionalised wound dressing for SAAP-148.

\section{Conclusions}

We found several factors that could have contributed to the poor antimicrobial effect of SAAP-148 in the pilot rat study: (i) the slow release profile of SAAP-148 from the 3:1 HM gel, (ii) the absorption of SAAP-148 by gauze and subsequently an incomplete release of the peptide from the wound dressing, (iii) the reduced bactericidal efficacy of SAAP-148 caused by the presence of the moist silicon wound contact layer Cuticell, and (iv) re-colonisation during the prolonged treatment time of $24 \mathrm{~h}$. After performing the adapted rat study with SAAP-148, we concluded that the main factors contributing to the poor antimicrobial effect of SAAP-148 were related to the wound micro-environment, i.e. components within the wound exudates and the relatively high bacterial load in the wounds.

\section{Supplementary information}

Supplementary information accompanies this paper at https://doi. org/10.1186/s12941-019-0336-7.

Additional file 1. SAAP-148 dosages to eradicate bacteria.

\section{Abbreviations}

AMPs: antimicrobial peptides; BWM: burn wound model; CFU: colony forming units; HM: hypromellose; LR: log reduction; LB: Luria-Bertani; MRSA: methicillin-resistant Staphylococcus aureus; PBS: phosphate-buffered saline; RPMI: Roswell Park Memorial Institute; SD: standard deviation; SPS: sodium polyanethol sulfonate; P/S: penicillin/streptomycin.

\section{Acknowledgements}

We thank Rika van der Laan and her colleagues (Amsterdam Animal Research Centre, Amsterdam, the Netherlands) for assisting the rat experiments. We also thank the animal welfare body officer Inge de Greeuw (Dept. of Animal Welfare VUNUMC, Amsterdam the Netherlands) for her technical support on the rat experiments.

\section{Authors' contributions}

GSD, MMWU, MV, EM and BKHLB performed the rat experiments. GSD performed the additional in vitro and ex vivo experiments. RAC, PHN and JWD supplied the novel antimicrobial peptide SAAP-148. All authors assisted with the interpretation of the data included in this manuscript. All authors read and approved the final manuscript.

\section{Funding}

The collaboration project was funded by the Ministry of Economic Affairs through the public-private partnership (PPP) allowance made available by Health-Holland, Top Sector life Sciences \& Health as well as by a contribution from the Dutch Burns Foundation, Madam Therapeutics B.V., Mölnlycke Health Care AB, Leiden University Medical Centre, Amsterdam University Medical Centre and the Association of Dutch Burn Centres (LSH-TKI40-43100-98-017).

\section{Availability of data and materials}

The datasets used and analyzed during the current study are available from the corresponding author on reasonable request.

\section{Ethics approval and consent to participate}

Human skin, eschar and blood were obtained according to institutional guidelines and medical research "code of conduct for responsible use", drafted by Federa (Foundation Federation of Dutch Medical Scientific Societies). The experimental protocols for the study of SAAP-148 in a rat model were approved by the Central Authority for Scientific Procedures on Animals (CCD Protocol AVD114002016601), according to governmental and international guidelines for animal experimentation.

\section{Consent for publication}

Not applicable.

\section{Competing interests}

The authors declare that they have no competing interests.

\section{Author details}

${ }^{1}$ Association of Dutch Burn Centres, Zeestraat 29, 1941 AJ Beverwijk, The Netherlands. ${ }^{2}$ Dept. of Infectious Diseases, Leiden University Medical Centre, Albinusdreef 2, 2333 ZA Leiden, The Netherlands. ${ }^{3}$ Dept. of Immunohematology and Blood Transfusion, Leiden University Medical Centre, Albinusdreef 2, 2333 ZA Leiden, The Netherlands. ${ }^{4}$ Dept. of Plastic Reconstructive \& Hand Surgery, Amsterdam University Medical Centres, Free University of Amsterdam, Amsterdam Movement Sciences, De Boelelaan 1117, 1081 HV Amsterdam, The Netherlands.

Received: 31 July 2019 Accepted: 8 November 2019

Published online: 03 December 2019

\section{References}

1. Levy SB, Marshall B. Antibacterial resistance worldwide: causes, challenges and responses. Nat Med. 2004;10:S122-9.

2. Hanberger H, Walther S, Leone M, Barie PS, Rello J, Lipman J, et al. Increased mortality associated with methicillin-resistant Staphylococcus 
aureus (MRSA) infection in the Intensive Care Unit: results from the EPIC II study. Int J Antimicrob Agents. 2011;38:331-5.

3. Sato T, Abe T, Ichioka S. Factors impairing cell proliferation in the granulation tissue of pressure ulcers: impact of bacterial burden. Wound Repair Regen. 2018;26:284-92.

4. Sang Y, Blecha F. Antimicrobial peptides and bacteriocins: alternatives to traditional antibiotics. Anim Heal Res Rev. 2008;9:227-35.

5. Beisswenger C, Bals R. Functions of antimicrobial peptides in host defense and immunity. Curr Protein Pept Sci. 2005;6:255-64.

6. Sørensen OE, Borregaard N, Cole AM. Antimicrobial peptides in innate immune responses. Trends Innate Immun. 2008;15:61-77.

7. Diamond G, Beckloff N, Weinberg A, Kisich KO. The roles of antimicrobial peptides in innate host defense. Curr Pharm Des. 2009;15:2377-92.

8. Lai Y, Gallo RL. AMPed up immunity: how antimicrobial peptides have multiple roles in immune defense. Trends Immunol. 2009;30:131-41.

9. Mangoni ML, McDermott AM, Zasloff M. Antimicrobial peptides and wound healing: biological and therapeutic considerations. Exp Dermatol. 2016;25:167-73

10. Otvos L, Ostorhazi E. Therapeutic utility of antibacterial peptides in wound healing. Expert Rev Anti Infect Ther. 2015;13:871-81.

11. Lohner K. Membrane-active antimicrobial peptides as template structures for novel antibiotic agents. Curr Top Med Chem. 2016;17:508-19.

12. de Breij A, Riool M, Cordfunke RA, Malanovic N, de Boer L, Koning Rl, et al. The antimicrobial peptide SAAP-148 combats drug-resistant bacteria and biofilms. Sci Transl Med. 2018;10:eaan4044.

13. Haisma EM, de Breij A, Chan H, van Dissel JT, Drijfhout JW, Hiemstra PS, et al. LL-37-Derived Peptides Eradicate Multidrug-Resistant Staphylococcus aureus from Thermally Wounded Human Skin Equivalents. Antimicrob Agents Chemother. 2014;58:4411-9.

14. Nell MJ, Tjabringa GS, Wafelman AR, Verrijk R, Hiemstra PS, Drijfhout JW, et al. Development of novel LL-37 derived antimicrobial peptides with LPS and LTA neutralizing and antimicrobial activities for therapeutic application. Peptides. 2006;27:649-60.

15. Haisma EM, Göblyös A, Ravensbergen B, Adriaans AE, Cordfunke RA, Schrumpf J, et al. Antimicrobial peptide P60.4Ac-containing creams and gel for eradication of methicillin-resistant Staphylococcus aureus from cultured skin and airway epithelial surfaces. Antimicrob Agents Chemother. 2016:60:4063-72.

16. Dijksteel GS, Nibbering PH, Ulrich MMW, Middelkoop E, Boekema BKHL. SPS-neutralization in tissue samples for efficacy testing of antimicrobial peptides. BMC Infect Dis. 2019. (In review).

17. Anderson MJ, David ML, Scholz M, Bull SJ, Morse D, Hulse-Stevens M, et al. Efficacy of skin and nasal povidone-iodine preparation against mupirocin-resistant methicillin-resistant Staphylococcus aureus and S. aureus within the anterior nares. Antimicrob Agents Chemother 2015;59:2765-73.

18. Sutton SVW, Proud DW, Rachui S, Brannan DK. Validation of microbial recovery from disinfectants. PDA J Pharm Sci Technol. 2002;56:255-66.

19. Boekema BKHL, Pool L, Ulrich MMW. The effect of a honey based gel and silver sulphadiazine on bacterial infections of in vitro burn wounds. Burns. 2013;39:754-9.

20. Ermolaeva SA, Varfolomeev AF, Chernukha MY, Yurov DS, Vasiliev MM, Kaminskaya AA, et al. Bactericidal effects of non-thermal argon plasma in vitro, in biofilms and in the animal model of infected wounds. J Med Microbiol. 2011;60:75-83.

21. Moncla BJ, Pryke K, Rohan LC, Graebing PW. Degradation of naturally occurring and engineered antimicrobial peptides by proteases. Adv Biosci Biotechnol. 2011;2:404-8.

22. Starr CG, Wimley WC. Antimicrobial peptides are degraded by the cytosolic proteases of human erythrocytes. Biochim Biophys Acta Biomembr. 2017:1859:2319-26.

23. Pappen FG, Qian W, Aleksejūniené J, de Toledo Leonardo R, Leonardo MR, Haapasalo M. Inhibition of sodium hypochlorite antimicrobial activity in the presence of bovine serum albumin. J Endod. 2010;36:268-71.

24. Quintana RM, Jardine AP, Montagner F, Fatturi Parolo CC, Morgental RD, Poli Kopper PM. Effect of human, dentin, albumin and lipopolysaccharide on the antibacteerial activity of endodontic activity of endodontic irrigants. J Conserv Dent. 2017;20:341-5.

25. Burian A, Wagner C, Stanek J, Manafi M, Bohmdorfer M, Jager W, et al. Plasma protein binding may reduce antimicrobial activity by preventing intra-bacterial uptake of antibiotics, for example clindamycin. J Antimicrob Chemother. 2011;66:134-7.

26. Bay L, Kragh KN, Eickhardt SR, Poulsen SS, Gjerdrum LMR, Ghathian K, et al. Bacterial aggregates establish at the edges of acute epidermal wounds. Adv Wound Care. 2018;7:105-13.

27. Tsai DM, Tracy LE, Lee CCY, Hackl F, Kiwanuka E, Minasian RA, et al. Full-thickness porcine burns infected with Staphylococcus aureus or Pseudomonas aeruginosa can be effectively treated with topical antibiotics. Wound Repair Regen. 2016;24:356-65.

28. Forde $E$, Devocelle M. Pro-moieties of antimicrobial peptide prodrugs. Molecules. 2015;20:1210-27.

29. Müsken M, Pawar V, Schwebs T, Bähre H, Felgner S, Weiss S, et al Breaking the Vicious cycle of antibiotic killing and regrowth of biofilmresiding Pseudomonas aeruginosa. Antimicrob Agents Chemother. 2018;62:e01635-017118.

30. Bechert K, Abraham SE. Pain management and wound care. J Am Col CertifWound Spec. 2009;1:65-71.

31. Weinberg K, Birdsall C, Vail D, Marano MA, Petrone SJ, Mansour HE. Pain and anxiety with burn dressing changes. J Burn Care Rehabil. 2000;21:157-61.

32. GhavamiNejad A, Rajan Unnithan A, Ramachandra Kurup Sasikala A Samarikhalaj $\mathrm{M}$, Thomas RG, Jeong YY, et al. Mussel-inspired electrospun nanofibers functionalized with size-controlled silver nanoparticles for wound dressing application. ACS Appl Mater Interfaces. 2015;7:12176-83.

33. Gomes AP, Mano JF, Queiroz JA, Gouveia IC. Incorporation of antimicrobial peptides on functionalized cotton gauzes for medical applications. Carbohydr Polym. 2015;127:451-61.

34. Miao J, Pangule RC, Paskaleva EE, Hwang EE, Kane RS, Linhardt RJ, et al. Lysostaphin-functionalized cellulose fibers with antistaphylococcal activity for wound healing applications. Biomaterials. 2011;32:9557-67.

\section{Publisher's Note}

Springer Nature remains neutral with regard to jurisdictional claims in published maps and institutional affiliations.

Ready to submit your research? Choose BMC and benefit from

- fast, convenient online submission

- thorough peer review by experienced researchers in your field

- rapid publication on acceptance

- support for research data, including large and complex data types

- gold Open Access which fosters wider collaboration and increased citations

- maximum visibility for your research: over $100 \mathrm{M}$ website views per year

At BMC, research is always in progress.

Learn more biomedcentral.com/submissions 